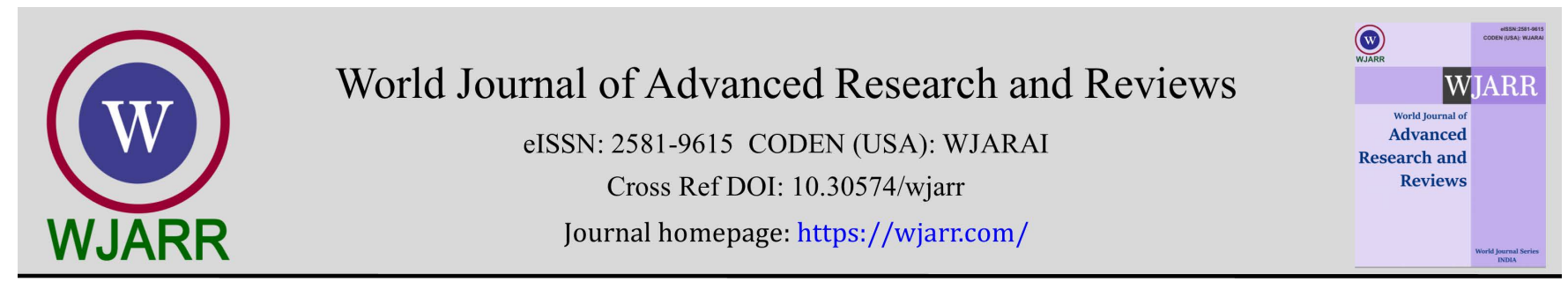

(REVIEW ARTICLE)

\title{
Delignification of Lignocellulosic Biomass
}

\author{
Deivy Andhika Permata 1, 2, ${ }^{*}$, Anwar Kasim ${ }^{2}$, Alfi Asben ${ }^{2}$ and Yusniwati 3 \\ ${ }^{1}$ Department of Agricultural Science, Faculty of Agriculture, Andalas University, Indonesia. \\ 2 Department of Agricultural Industrial Technology, Faculty of Agricultural Technology, Andalas University, Indonesia. \\ 3 Department of Agrotechnology, Faculty of Agriculture, Andalas University, Indonesia.
}

World Journal of Advanced Research and Reviews, 2021, 12(02), 462-469

Publication history: Received on 15 October 2021; revised on 20 November 2021; accepted on 22 November 2021

Article DOI: https://doi.org/10.30574/wjarr.2021.12.2.0618

\begin{abstract}
Delignification is the process of breaking lignocellulose into lignin, cellulose, and hemicellulose. The presence of lignin in lignocellulosic materials results in the limited utilization of cellulose. This article discusses lignin and the delignification process. There are various delignification methods from the literature study, namely physical, chemical, semi-chemical, mechanical, and enzymatic.
\end{abstract}

Keywords: Biodelignification; Delignification; Lignin; Lignocellulosic

\section{Introduction}

Lignin is a component of lignocellulosic material that is relatively difficult to degrade. Its existence limits the use of lignocellulosic materials in the industrial world. Lignin forms strong bonds with polysaccharides. This bond prevents solutions or enzymes from breaking down cellulose and hemicellulose, making it difficult to separate them in the fiber preparation process.

Lignocellulosic bioconversion can produce several products that have economic value, such as a source of sugar for the bioethanol industry (1-3). Utilization of lignocellulosic material as a source of glucose in bioethanol by hydrolyzing cellulose, but this is constrained because the cellulose is firmly bound to lignin. In the pulp and paper industry, lignin is undesirable because lignin causes a brown color in the paper. For this problem to be overcome, it is necessary to carry out a delignification process.

Delignification is a process of reducing lignin. This process breaks down lignocellulose into lignin, cellulose, and hemicellulose. Delignification can be mechanically, chemically, or biologically (biodelignification). This paper is a review of the delignification process. This article can add information regarding the delignification process.

\section{Anatomy of lignocellulosic biomass}

Lignocellulose contains three main components, namely lignin (10-25\%), hemicellulose (20-35\%), and cellulose (35$50 \%$ ) (Figure 1) (4), belongs to macromolecules. Besides that, there are other compounds known as micromolecular (low molecular weight) substances.

\footnotetext{
* Corresponding author: Deivy Andhika Permata

Department of Agricultural Science, Faculty of Agriculture, Andalas University, Indonesia.

Copyright $(2021$ Author(s) retain the copyright of this article. This article is published under the terms of the Creative Commons Attribution Liscense 4.0.
} 


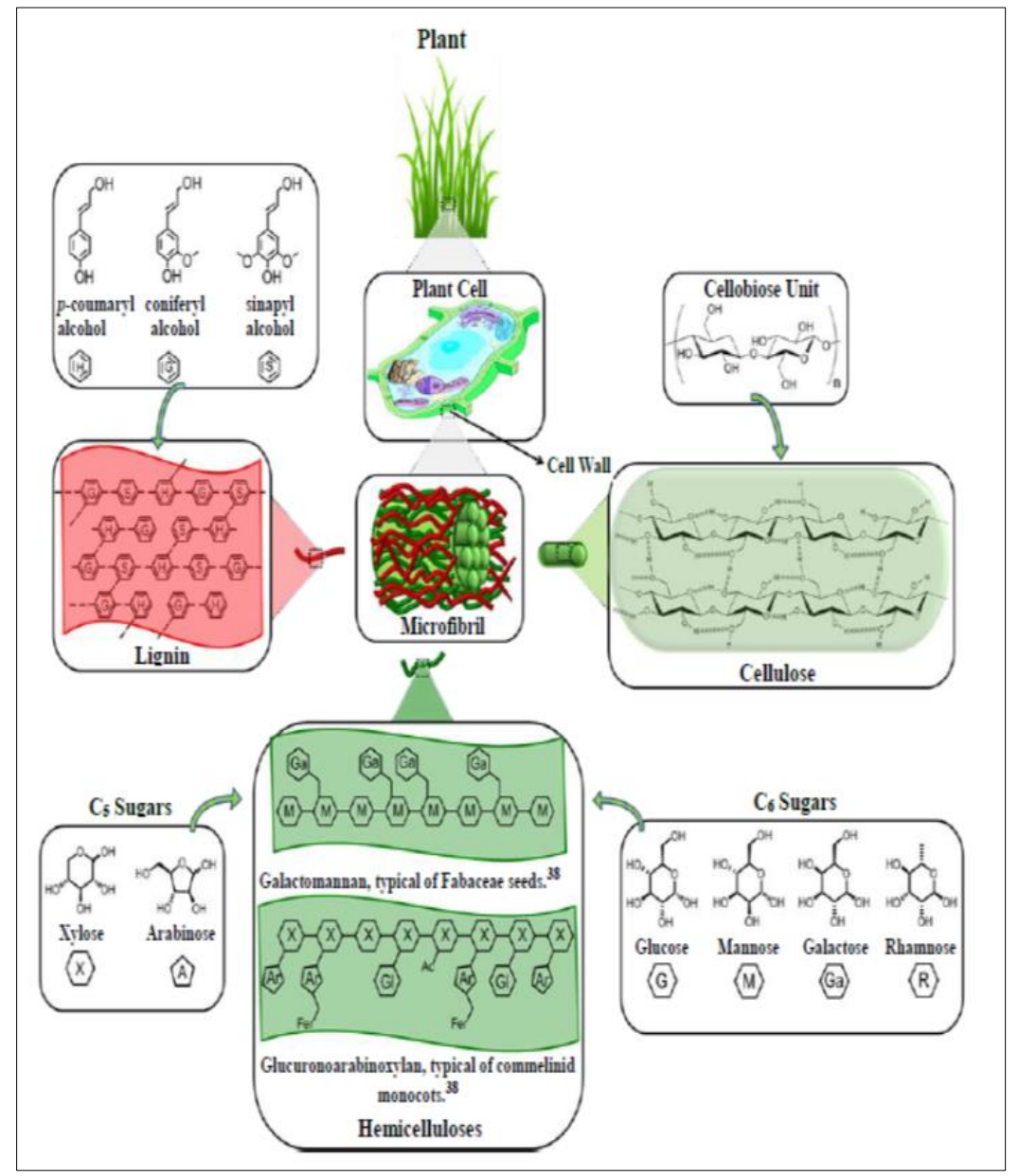

Figure 1 Main components and structure of lignocellulose "GI" represents glucuronic acid and "Fer" represents esterification with ferulic acid, which is characteristic of xylans in monocots (4)

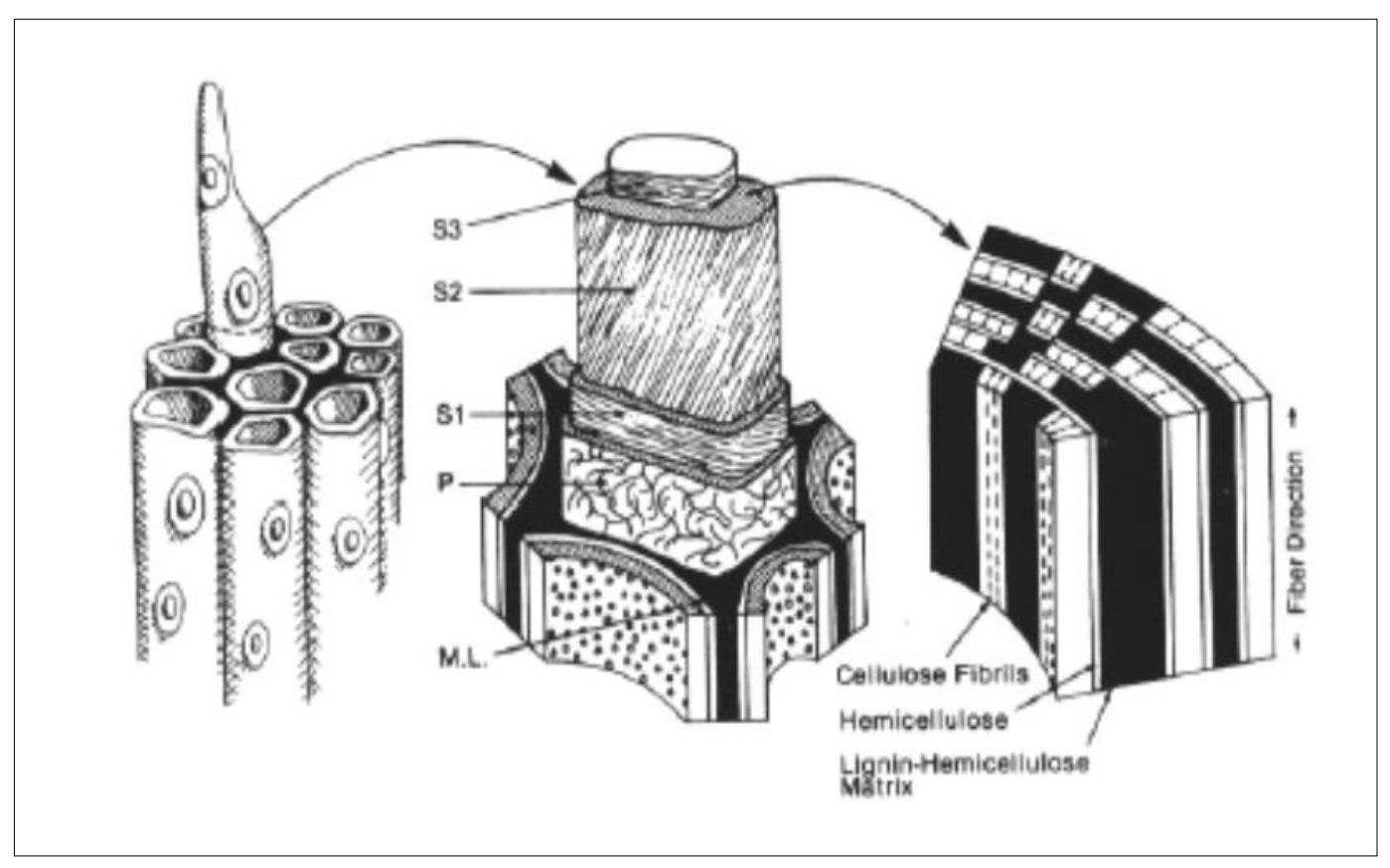

Figure 2 Plant cell wall configuration 
Figure 2 shows the arrangement of the plant cell wall consisting of the middle lamella (ML), the primary wall (P), and the secondary wall (S). The secondary wall consists of the transition lamella (S1), the primary-secondary wall (S2), and the inner secondary wall (S3). The primary wall is $0.1-0.2 \mathrm{~m}$ thick and contains a network of cellulose microfibrils surrounding the secondary wall. Cellulose in each layer of the secondary wall is formed as a thin sheet, composed of long chains of -D-glucopyranose residues linked by $-1,4$ glucoside bonds, called primary fibers. Many primary fibers, when woven laterally, form microfibrils. These microfibrils have a different structure and orientation in each layer of the cell wall. The S1 layer has a cross-fiber structure, the S2 layer has microfibrils parallel to the lumen axis, and the S3 layer has helical microfibrils. The microfibrils are surrounded by hemicellulose and lignin. The middle lamella (M), filled by hemicellulose and lignin, is the part between the two cell walls. Hemicellulose is covalently bonded to lignin. Cellulose is naturally protected from degradation in the presence of hemicellulose and lignin (5).

\section{The mechanism of lignin degradation}

Lignin is a polymer with an aromatic structure formed through phenylpropane units linked together by several bonds. Lignin is challenging to degrade because of its complex and heterogeneous system, which binds to cellulose and hemicellulose in plant tissues. More than 30 percent of plants are composed of lignin which gives them a solid shape and provides protection against insects and pathogens. Besides offering a firm body to plants, lignin also forms strong bonds with polysaccharides that protect polysaccharides from microbial degradation and form lignocellulosic structures. Lignin is mainly concentrated in the middle lamella and S2 layer of the cell wall, which is formed during the lignification process of plant tissue (6). Lignin not only hardens cellulose microfibrils it also physically and chemically binds to hemicellulose. Lignin is formed by three-dimensional polymerization of derivatives (Fig. 3) of cinnamyl alcohol $\rho$-coumaryl alcohol, coniferyl alcohol, and sinapyl alcohol (5) with a molecular weight of up to 11,000. Lignin that protects cellulose is resistant to hydrolysis due to the presence of arylalkyl and ether bonds (Figure 4). Arylgycerol-Baryl ether groups as the primary bond, while the phenolic-hydroxyl, methoxyl, hydroxyl, and benzyl alcohol groups as additional bonds that affect the reactivity of lignin in interacting with cellulose microfibrils so that lignin has a high molecular weight, branched structure to form three dimensions, and is hydrophobic or insoluble in water. The largest concentration of lignin is found in the middle lamella and gets smaller in the secondary wall layer or plasma membrane (7).

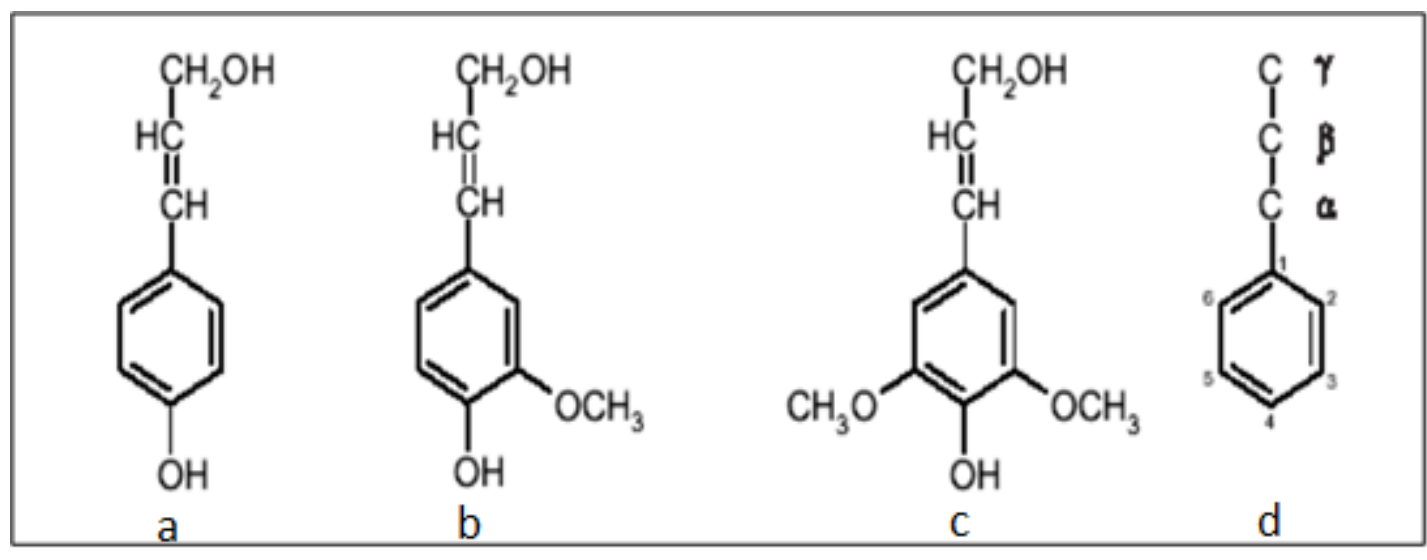

Figure 3 Lignin composition unit para coumaryl alcohol (a), coniferyl alcohol (b), synapyl alcohol (c), and skeletal model (d) (5)

The formation of lignin occurs intensively after cell wall thickening stops, starting from the primary wall and proceeding to the secondary wall. Lignin factors in limiting the permeability of plant cell walls can be divided into chemical and physical effects. The chemical effect is related to lignin-carbohydrate and hemicellulose acetylation. Lignin physically encloses microfibrils in a hydrophobic matrix and is covalently bonded to hemicellulose. The relationship between these carbohydrate lignins plays a role in preventing the hydrolysis of cellulose polymers (8).

Many studies with radioactive carbon (14C) confirm that p-hydroxynamyl alcohol p-coumaryl alcohol, coniferyl alcohol, and sinapyl alcohol are the primary parent compounds and are the building blocks of all lignin. Figure 5 below gives an overview of the main steps for the formation of lignin parent compounds. Lignin biosynthesis begins with glucose obtained from photosynthesis. It is converted to shikimic acid, an intermediate of the shikimic acid pathway. 


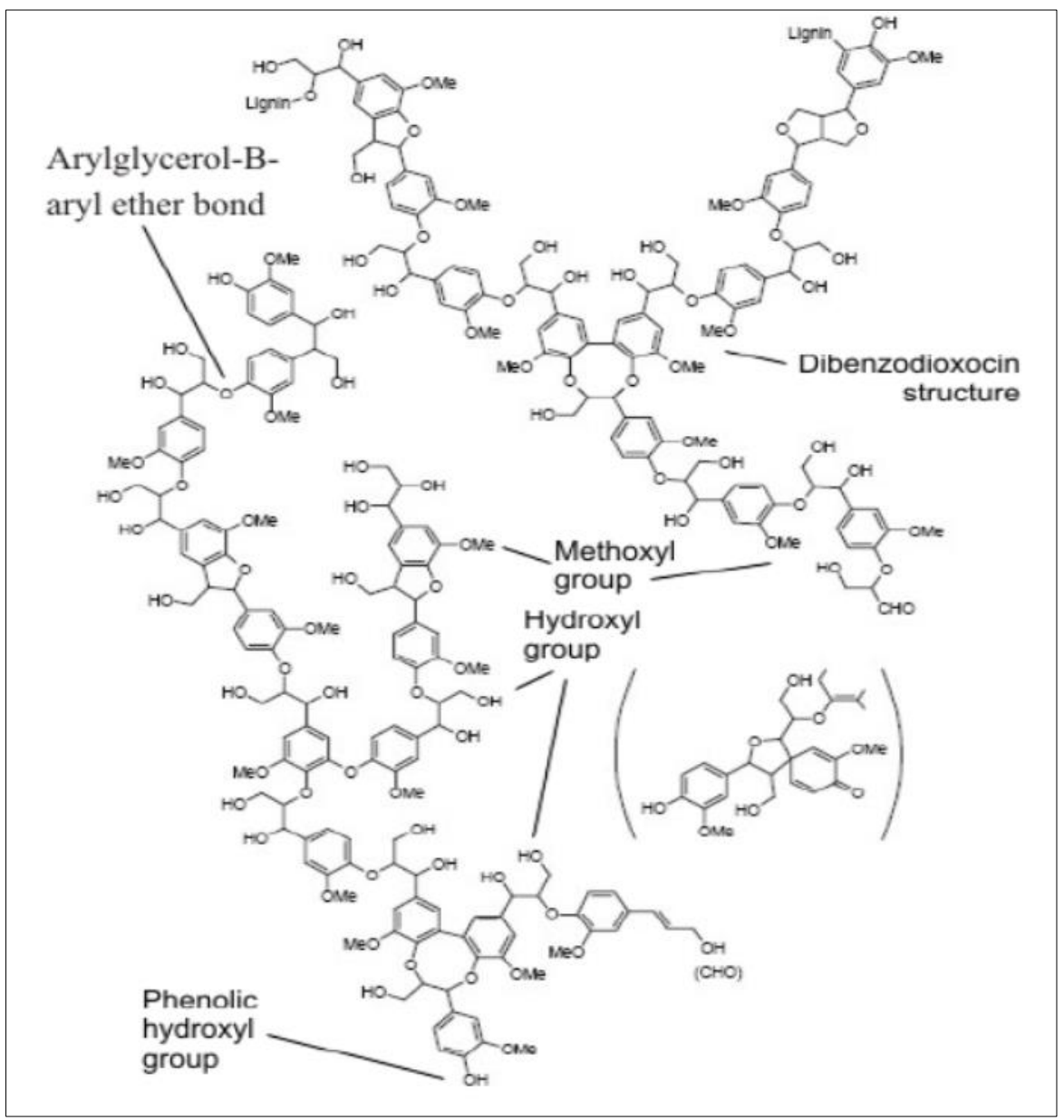

Figure 4 Structural and functional groups of polymers (7)



Figure 5 Metabolic pathway from glucose to parent compound phenylpropane lignin (9) 
The two aromatic amino acids L-phenylalanine and L-tyrosine are formed by reductive amination via prephenic acid as the final compound of the path. On the other hand, they are the starting agents (amino acid group) for the enzymatic metabolism of phenyl propanoid (cinnamic acid pathway), producing not only three cinamyl alcohols via activated cinnamic acid derivatives but also extractive components such as flavonoids or stilbenes. Amino acids are deaminated by deaminase (phenylalanine amino lyase and tyrosine amino lyase) to the corresponding cinnamic acid. The further significant steps are hydroxylation (by phenolase (hydrolase)) and methylation (by o-methyltransferase) to yield pcoumaric acid, kefeic acid, ferulic acid, 5-hydroxy- and synaptic acid. The regulation of lignin production is controlled early on by different deaminase activities under various conditions in factors such as light and hormone availability. Cinamyl alcohol is formed by the enzymatic activity (CoA ligase) and reduction (NADP reductase, NADP hydrogenase) of the corresponding acids via coenzyme-A thioesters and aldehydes (9).

\subsection{Lignin degradation method}

\subsubsection{Physically}

The hydrothermal method is carried out so that lignin can decompose optimally. Lignin is a polymer consisting of three types of phenyl propionic alcohol monomers: conifer alcohol, para coumaryl alcohol, and synapsil alcohol; the three types of monomers have different substitutions patterns. Lignin is ether-linked ( $\alpha-0-4$ ' and $\beta-0-4$ ') between monomers. The hydrothermal method can break down $\beta-0-4$ ' and ether with an acid catalyst so that the depolymerization process can occur (10).

\subsubsection{Chemically}

Chemical treatments include using $\mathrm{HCl}(11), \mathrm{NaOH}(12)$, and ionic solutions ionik $(13,14)$. Among these solvents, the best used is $\mathrm{NaOH}$ (Figure 6). Hemicellulose has an amorphous structure so that the use of $\mathrm{NaOH}$ can remove lignin while extracting hemicellulose (15). $\mathrm{NaOH}$ solution can attack and damage the lignin structure in the crystalline and amorphous parts and separate some hemicelluloses. $\mathrm{OH}$ ions from $\mathrm{NaOH}$ will break bonds from the basic structure of lignin, while $\mathrm{Na}^{+}$ions will bind to lignin to form sodium phenolate. This phenolic salt is soluble. Dissolved lignin is marked with black color in the solution, which is called black leachate (16).

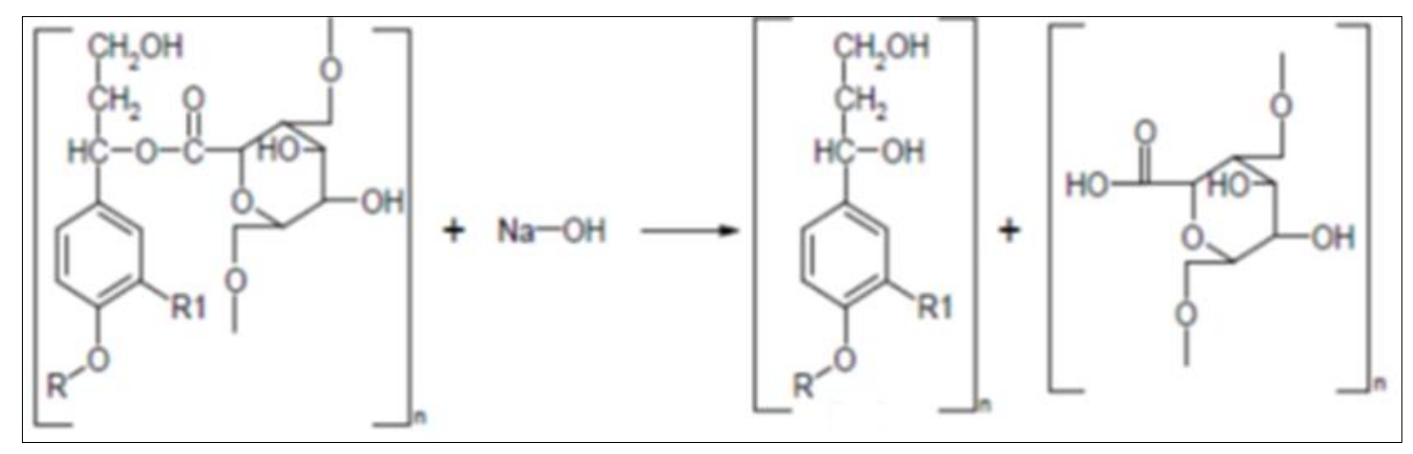

Figure 6 Mechanism of bond breaking between lignin and cellulose using $\mathrm{NaOH}(16)$

Complete oxidation of lignin produces aromatic compounds such as syringaldehyde, vanillin, and ferulic acid. The final breakdown of these compounds has organic acids, carbon dioxide, methane, and water. The use of chemicals can degrade lignin by $41.17 \%$ (17).

- Mechanically, the process is straightforward and does not use chemicals. In this process, the content of lignin and other substances is still high.

- Semi-chemically, this process is a combination of chemical and mechanical processes. The fibers are separated chemically, while the parts that are not crushed are separated mechanically. This method is only able to degrade lignin by $4.2 \%$ (18).

\subsubsection{Enzymatically}

This process uses ligninase enzymes, which generally consist of two main groups: laccase (Lac) and peroxidase. Peroxidase enzymes consist of lignin peroxidase (LiP) and manganese peroxidase (MnP) (19). According to (19). laccase (EC 1.10.3.2, Lac) is a copper-containing oxidized phenol that does not require $\mathrm{H}_{2} \mathrm{O}_{2}$ but uses molecular oxygen. Laccase can reduce $\mathrm{O}_{2}$ to $\mathrm{H}_{2} \mathrm{O}$ in phenolic substrates through a one-electron reaction to form free radicals, which can be equated 
with cation radicals included in the MnP reaction. The presence of mediators such as ABTS (2,2-azinobis(3ethylbenzothiazoline-6-sulphonate)) or HBT (hydroxybenzotriazole), makes laccase able to oxidize certain nonphenolic compounds and veratryl alcohol. Lignin peroxidase can catalyze several oxidation reactions, including the breakdown of the $C_{\alpha}-C_{\beta}$ bond of the non-phenolic propyl side chain of the aromatic component of lignin and benzyl alcohol oxidation of phenol and breakdown of the aromatic ring of non-phenolic components of lignin compounds (20). Lignin peroxidase oxidizes aromatic nuclei (phenolic and non-phenolic) by losing one electron to produce cation and phenoxy radicals (19). Manganese peroxidase (EC 1.11.1.13, MnP) is an extracellular heme peroxidase that requires $\mathrm{Mn}^{2+}$ to reduce substrate. Maganase peroxidase can oxidize $\mathrm{Mn}^{2+}$ to $\mathrm{Mn}^{3+}$. The $\mathrm{Mn}^{3+}$ formed is highly reactive and forms complexes with organic acids and diffuses away from the enzyme to oxidize other materials such as lignin. The phenolic structure of lignin is then oxidized to phenoxyl radicals. The resulting phenoxyl radicals react further by demethylation, alkyl-phenyl cleavage, $C_{\alpha}$ oxidation, or $C_{\alpha}-C_{\beta}$ bond cleavage (20). Several studies have suggested the ability of microorganisms such as molds and bacteria to produce ligninase. Microorganisms that play a role include Pleurotus floridanus (21), Trametes versicolor (22), Phanerochaete chrysosporium (23,24), Ganoderma boninense (25), Trichoderma viride (26), Aspergillus niger and Phanerochaete (27), Bacillus atrophaeus and B. pumilus (28), Streptomyces ipomoea (29), and B. subtilis, Klebsiella pneumonia (30), Actinomycetes (31). Table 1 shows the percentage of lignin reduction with the help of microorganisms.

Table 1 The percentage of lignin reduction

\begin{tabular}{|l|c|c|}
\hline Microorganisms & Percentage of Lignin Decrease (\%) & References \\
\hline Pleurotus floridanus & 79.7 & $(21)$ \\
\hline P. chrysosporium & 36.40 & $(32)$ \\
\hline Actinomycetes & 10.27 & $(33)$ \\
\hline Trametes versicolor & 37.31 & $(22)$ \\
\hline Trichoderma viride and Escherichia coli & 18.57 & $(26)$ \\
\hline
\end{tabular}

\section{Conclusion}

Delignification is the process of reducing lignin and breaking lignocellulose into lignin, cellulose, and hemicellulose. The literature study results suggest various methods of delignification, namely physical, chemical, semi-chemical, mechanical, and enzymatic.

\section{Compliance with ethical standards}

\section{Acknowledgments}

Thank you to Andalas University for making it possible to publish this review article.

\section{Disclosure of conflict of interest}

The authors state that there are no conflicts of interest in the publication of this article.

\section{References}

[1] Sudiyani Y, Heru R, Alawiyah S. Utilization of lignocellulosic waste biomass for bioethanol as a new renewable energy source, Ecolab. 2010; 4(1): 1-54.

[2] Kim S, Kim CH. Bioethanol production using the sequential acid/alkali-pretreated empty palm fruit bunch fiber, Renew. Energy. 2013; 54: 150-155.

[3] Muryanto, Sahlan M, Sudiyani Y. Simultaneous saccharification and fermentation of oil palm empty fruit bunch for bioethanol production by Rhizopus oryzae., Int. J. Environ. Bioenergy. 2012; 3(2): 111-120.

[4] Isikgor FH, Becer CR. Polymer chemistry the production of bio-based chemicals and polymers, Polym. Chem. 2015; 6: 4497-4559. 
[5] Perez J, Munoz-Dorado J, Rubia TD la, Martinez J. Biodegradation and biological treatment of cellulose, hemicellulose and lignin; an overview," Int. Microb. 2002; 5: 53-56.

[6] Steffen KT. Degradation of recalcitrant biopolymers and polycyclic aromatic hydrocarbons by litter-decomposing basidiomycetous fungi, University of Helsinki. 2003.

[7] Del Campo I. Dilueted acid hydrolisis pretreatmentnof agri food waste for bioethanol production. Ind Crops Prod. 2006;24:214-21

[8] Chahal PS, Chahal DS. Lignocellulosic waste: biological conversion, in bioconversion of waste materials to industrial products, 2nd ed., London: Blackie Academic \& Professional. 1998; 376-422.

[9] Fengel D, Wegener G, Wood chemistry, ultrastructure, reactions. Yogyakarta: Gajah Mada University Press. 1983.

[10] Zhao J, Quan C, Fan S. Role of lignin in bio-ethanol production from lignocellulosic biomass, J. Biobased Mater. Bioenergy. 2013; 7(5): 533-540.

[11] Handayani SS, Tarnanda R, Rahayu BA, Amrullah. The process of delignification of lignin in tobacco stem waste as preparation for ethanol production, J.Oijar MIPA. 2018; 13(2): 140-146.

[12] Muryanto M, Sudiyani Y, Abimanyu H. Optimization of the NaOH pre-treatment process of oil palm empty fruit bunches to become bioethanol, J. Kim. Terap. Indones. 2016; 18(01): 27-35.

[13] Domínguez de María P. Recent trends in (ligno)cellulose dissolution using neoteric solvents: switchable, distillable and bio-based ionic liquids," J. Chem. Technol. Biotechnol. 2014; 89: 11-18.

[14] Sen S, Binder J, Raines R, Maravelias C. Conversion of biomass to sugars via ionic liquid hydrolysis: process synthesis and economic evaluation," Biofuels Bioprod. Biorefin. 2012; 6: 444-452.

[15] Julfana R. Enzymatic hydrolysis of cellulose from sago dregs using a mixture of cellulases from Trichoderma reesei and Aspergillus niger, J. Kim. Katulistiwa. 2012; 2(1): 52-57.

[16] Safaria S. The effectiveness of cellulase enzyme mixture from Aspergillus niger and Trichoderma reesei in hydrolyzing coconut coir substrate, J. Kim. Khatulistiwa. 2013; 2(1): 46-51.

[17] Handayani SS, Tarnanda R, Rahayu BA, Amrullah. Lignin degradation process in tobacco stem waste as a preparation for lignin bioethanol production, J. Pijar. MIPA. 2018; 13(2): 140-146.

[18] Ni'mah F, Argo BD, Lutfi M, Maharani DM, Putranto AW. Comparison of rice straw lignin degradation pretreatment process with wet milling and dry milling in bioethanol production, J. Teknol. Pertan. 2014; 15(2): 77-84.

[19] Prenafeta-Boldú FX, de Hoog GS, Summerbell RC. Fungal communities in hydrocarbon degradation. 2019.

[20] Reid ID. Biodegradation of lignin, Can. J. Bot. 1995; 73(S1): 1011-1018.

[21] Lukitawesa, Millati R, Cahyanto MN. Effect of cut size on the growth of Pleurotus floridanus LIPIMC 996 and delignification results during preliminary treatment of oil palm empty fruit bunches, Agritech. 2012; 32(4): 346351.

[22] Azhari A, Falah S, Nurjannah L, Bintang M. Sengon trunk delignification by Trametes versicolor, Curr. Biochem. 2014; 1(1): 1-10.

[23] Nurhasni N, Larasati TRD, Iksan A. Delignification of sawdust white teak (Gmelina arborea Roxb.) by fungi Phanerochaete chrysosporium irradiated gamma ray," J. Kim. Val. 2016; 2(2): 104-113.

[24] Coconi Linares N, Fernández F, Loske AM, Gómez-Lim MA, MA Gómez-Lim. Enhanced delignification of lignocellulosic biomass by recombinant fungus Phanerochaete chrysosporium overexpressing laccases and peroxidases, J. Mol. Microbiol. Biotechnol. 2018; 28(1): 1-3.

[25] Jumali SS, Ismail S. Ganoderma boninense Efficacy in delignifying oil palm empty fruit bunches, Sci. Technol. 2017; 25: $1-8$.

[26] Prasetya D, Panjiarto WP, Soetaredjo FE. Bio-delignification of oil palm empty fruit bunch of using Trichoderma viride and Escherichia Coli, ARPN J. Eng. Appl. Sci. 2018; 13(2): 529-535.

[27] Supriyatna A. Increasing nutrition of rice straw through fermentation using Phanerochaete chrysosporium and Aspergillus niger mushrooms consortium. J Istek. 2017;X(2):166-81. 
[28] Gonzalo G De, Colpa DI, Habib MHM, Fraaije MW. Bacterial enzymes involved in lignin degradation, J. Biotechnol. 2016; 236: 110-119.

[29] Margot J, Bennati-Granier C, Maillard J, Blánquez P, Barry DA, Holliger C. Bacterial versus fungal laccase: potential for micropollutant degradation," AMB Express. 2013; 3: 63.

[30] Yadav S, Chandra R. Syntrophic co-culture of Bacillus subtilis and Klebsiella pneumonia for degradation of kraft lignin discharged from rayon grade pulp industry, J. Environ. Sci. 2015; 3: 229-238.

[31] HT Prakoso, H Widiastuti, Suharyanto, Siswanto. Exploration and characterization of ligninolytic aerobic bacteria and their application for composting oil palm empty fruit bunches, Menara Perkeb. 2014; 82(1): 15-24.

[32] Noferdiman, Yani A. Nutrient content of palm mud fermented with mushroom P. chrysosporium, Agripet. 2013; 13(2): 47-52.

[33] Satria H, Nurhasanah, Nurhasanah. Lignin degradation by local isolates of Actinomycetes on rice straw waste substrate, J. Sain MIPA. 2015; 16(3): 135-142. 